\title{
A Case Report on an Asymptomatic Labial Fusion in a Woman of Reproductive Age
}

\author{
Fatema Al-Hubaishi*, Fadheela Al-Najjar and Aysha Salah Al-Medfa
}

Department of Obstetrics and Gynecology, Alkindi Specialized Hospital, Zinj, Kingdom of Bahrain

*Corresponding author: Fatema Al-Hubaishi, Department of Obstetrics and Gynecology, Alkindi Specialized Hospital, Zinj, Kingdom of Bahrain, Tel: 00973 39050708; E-mail: fatemaalhubaishi@gmail.com

Rec date: December 04, 2017; Acc date: February 06, 2018; Pub date: February 09, 2018

Citation: Al-Hubaishi F, Al-Najjar F, Al-Medfa AS (2018) A Case Report on an Asymptomatic Labial Fusion in a Woman of Reproductive Age. Gynecol Obstet Case Rep Vol.4:No.1:60

\section{Abstract}

Labial adhesions are extremely rare in reproductive age groups. Only a few cases were described in the literature. We report a female patient with an incidental finding of labial adhesions. The patient was a 24-year-old woman, not a known case of any medical illnesses, presented with asymptomatic labial adhesions, incidentally found on shaving. Clinical examination revealed normally developed Labia majora, adhered at the lower part just above the vaginal opening. Labia minora were partially but extensively fused, covering the clitoral hood. Intraoperatively, labial fusion was dissected with lectrocautery under general anesthesia. Postoperatively, on follow up, the adhesions were completely separated, and the area healed. No recurrence.

Keywords: Labial fusion; Labial adhesion

\section{Introduction}

Labial adhesion (also called labial agglutination and synechia vulvae) is a common vaginal condition estimated to occur in $0.6 \%-5 \%$ of prepubertal girls [1], with a peak incidence of up to 3 percent of girls in the second year of life [2] However, this condition is a rare clinical entity in adults [3]; only a few cases have been reported in the literature; predominantly occurring in postmenopausal women rather than in reproductive ages [4]. Labial adhesions may be partial, involving only the upper or lower labia, or complete [2].

The majority of the reported cases are asymptomatic. Rarely, they may present with urinary incontinence, urinary tract infections, vaginitis, hematuria, dysuria or dyspareunia [1]. The etiological factors reported to contribute to Labial adhesions are chronic vaginal inflammation, hypoestrogenism, lack of sexual activity, local trauma, circumcision, vaginal lacerations in childbirth, recurrent urinary tract infections and lichen sclerosus. Furthermore, labial adhesions can rarely occur idiopathically, without any evidence of the above $[5,6]$. In this article, we describe a case of extensive labial fusion as an incidental finding in an asymptomatic reproductive age woman, it's management and literature review.

\section{Case Report}

A 24-year-old, female presented to the outpatient Gynaecology department complaining of fused labia, that she incidentally found while shaving. The patient is asymptomatic; and is sexually inactive.

She had a history of regular menstrual cycles since menarche (at the age of 12 years). Her personal medical history was unremarkable. No history of sexual assault.

Gynecological examination revealed Extensive adhesion of the labia minora, covering the clitoral hood completely. The labia majora was normal in shape but fused at the lower border just above the vaginal opening. The urethral orifice and the vaginal opening were visualized and normal (Figure 1).

Urinalysis and urine culture were negative for infection. The patient was not investigated for any sexually transmitted diseases. Hormonal analysis revealed normal estrogen and gonadotropin levels as seen in Table 1.

Pelvic ultrasonography and MRI were not done. Under general anesthesia, in the lithotomy position, inspection of the external genitalia revealed fused labia minora, clitoral hood could not be retracted, and the surrounding vulva appeared white and atrophic. The degree of adhesion was such that the clitoral hood could not be seen.

The labia majora was partially fused at the lower border just above the vaginal opening. The Vaginal opening and the urethral orifice were visualized and normal. Labial adhesions were released by electrocautery and the released edges were sutured (Figure 2). A pack containing fusidic acid was applied for 24 hours.

Postoperatively, the patient was discharged with daily topical Fucidin ointment, to be applied for four weeks. Labia Minora over the clitoral hood was not released as it was extensively fused and atrophied. Reconstructive surgery is needed for such release (Figure $\mathbf{3}$ ).

On her postoperative follow up at the end of six weeks, labial tissues were found to be completely healed (Figure 4). 


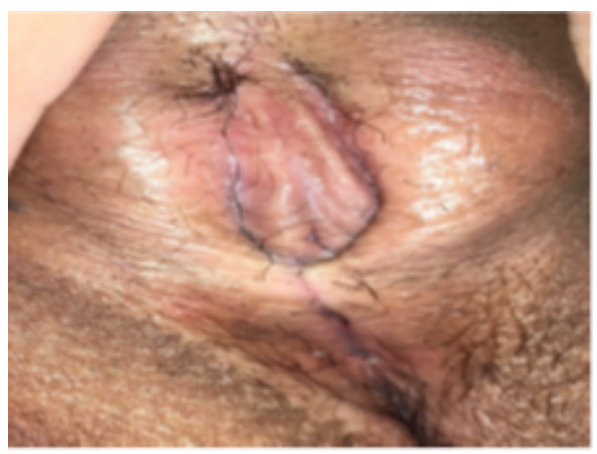

Figure 1 Preoperative view of labial fusion.

Table 1 Results of the patient's hormone assay.

\begin{tabular}{|c|c|}
\hline Test & Result \\
\hline FSH & $5.5 \mathrm{mlU} / \mathrm{ml}$ \\
\hline LH & $3 \mathrm{mlU} / \mathrm{ml}$ \\
\hline Estrogen & $110 \mathrm{pg} / \mathrm{ml}$ \\
\hline Progesterone & $1.3 \mathrm{ng} / \mathrm{ml}$ \\
\hline
\end{tabular}

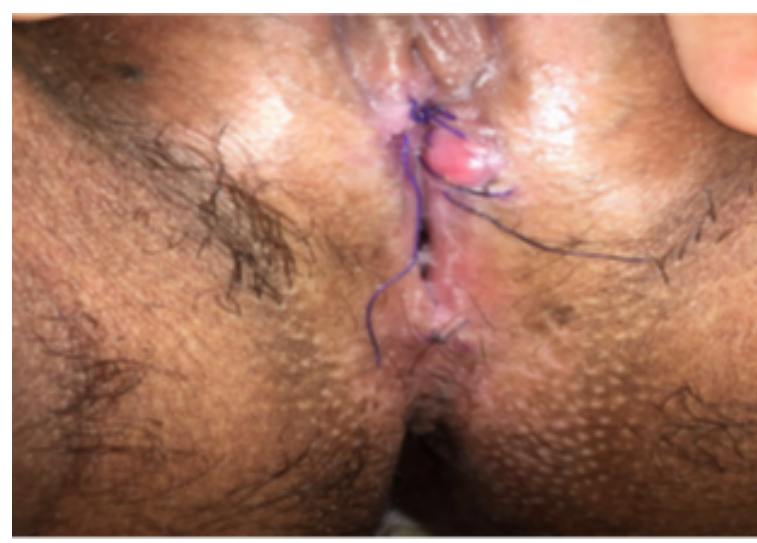

Figure 2 Post-operative view of sutured edges of released adhesions.

\section{Discussion}

Labial fusion, a common vaginal condition in children, is a rare clinical entity in adults, occurring more rarely in reproductive age women. The relative hypoestrogenic environment and sexual abuse/genital trauma are suggested as the main predisposing factors of this disorder in prepubertal girls. As for adults, Labial fusion is associated with recurrent urinary tract infections, vulvovaginitis, genital trauma, hypoestrogenism and lack of sexual activity, with a few cases which were diagnosed as lichen sclerosis after punch biopsy $[5,7]$.

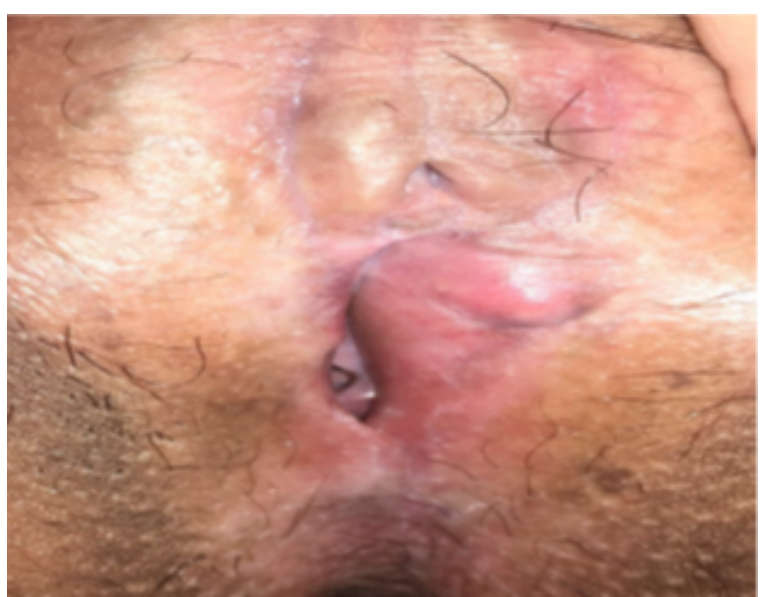

Figure 3 View of the fusion at the clitoral hood.

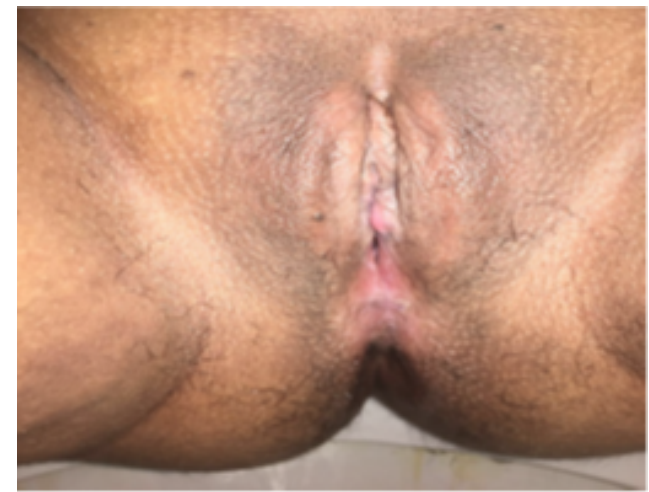

Figure 4 Post-operative view of the case at 6 weeks.

We can exclude hypoestrogenemia as the cause of labial fusion in our patient with a history of regular menses. She did not state any history of sexual abuse or genital trauma either; both of which have been reported as possible causes of Labial fusion in reproductive age females. Despite the extensive adhesions, our patient was symptomatic. The general initial therapy for superficial labial adhesions is estrogen cream. Particularly, in prepubertal and postmenopausal women as it might reduce the irritation of the vaginal mucosa and hence aid in subsequent repair [8,9]. In patients with complete, thick adhesions and a long history of Labial fusion. Our patient's age, status and her wish of expeditious treatment made us choose surgery instead of topical therapy. Complete healing was achieved in 6 weeks with no further complaints. As per the adhesions, our patient would have had sexual dysfunction/ dyspareunia if she was sexually active.

\section{Conclusion}

Labial fusion is a rare event in reproductive women. However, it should be considered in the differential diagnoses of the patients presenting with sexual dysfunction. 


\section{Acknowledgements}

The woman whose story is told in this case report has provided signed permission for its publication.

\section{References}

1. Mayoglou L, Dulabon L, Martin-Alguacil N, Pfaff D, Schober J (2009) Success of treatment modalities for labial fusion: A retrospective evaluation of topical and surgical treatments. J Pediatr Adolesc Gynecol 22: 247-250.

2. Bacon JL, Romano ME, Quint EH (2015) Clinical recommendation: Labial adhesions. J Pediatr Adolesc Gynecol 28: 405.

3. Tsujita Y, Asakuma J, Kanbara T, Yoshii T, Azuma R, et al. (2010) A case of labial adhesion in a reproductive woman. Europe PMC 56: 463-465.

4. Ozekinc M, Yucel S, Sanhal C, Erman Akar M (2013) Labial fusion causing coital and voiding difficulty in a young woman. Adv Sexual Med 3: 11-13.
5. Kumar RK, Sonika A, Charu C, Sunesh K, Neena M (2005) Labial adhesions in pubertal girls. Arch Gynecol Obst 243-245.

6. Uei T, Katou Y, Shimizu N, Yamanaka H, Seki M, et al. (2000) Labial adhesion in a reproductive woman with difficulties of sexual intercourse and urination: A case report. Hinyokika Kiyo 46: 433-436.

7. Lambert B (2004) Complete adult vulvar fusion: A case report. J Obstet Gynaecol Can 26: 501-502.

8. Dirim A, Hasirci E (2011) Labial fusion causing urinary incontinence and recurrent urinary tract infection in a postmenopausal female: A case report. Int Urogynecol J 22: 119-120.

9. Muppala H, Meskhi A (2009) Voiding dysfunction due to longstanding labial fusion in an elderly woman: a case report. Int Urogynecol J 20: 25-32. 